\title{
Transaction
}

\section{Morphological Studies on Assembling Behavior of Oligopeptides Obtained by Dissolution of Feather Keratin with Alkali}

\author{
Yutaka Kawahara $^{* 1}$, Makoto Ikegami $^{* 2}$, Atsushi Nakayama ${ }^{* 1}$, Yuichi Tsuda ${ }^{* 3}$, \\ Seiji Kenjo ${ }^{* 3}$, and Masaki Tsuji ${ }^{* 4}$ \\ ${ }^{* 1}$ Department of Chemistry and Chemical Biology, Graduate School of Engineering, Gunma University, \\ 1-5-1 Tenjin-cho, Kiryu, Gunma 376-8515, Japan \\ ${ }^{* 2}$ Graduate School of Science and Technology, Kyoto Institute of Technology, \\ Matsugasaki, Sakyo-ku, Kyoto 606-8585, Japan \\ ${ }^{* 3}$ Toyo Feather Industry Co. Ltd., 2-26-5 Fuchinobe, Sagamihara, Kanagawa 229-0006, Japan \\ ${ }^{* 4}$ Institute for Chemical Research, Kyoto University, Uji, Kyoto-fu 611-0011, Japan
}

\begin{abstract}
The self-assembling behavior for the oligopeptides obtained from the dissolution of feather keratins via the alkaline hydrolysis process was investigated. The entities generated from the aqueous solution of oligopeptides showed a dendrite-like and non-birefringent structure. To enhance the molecular orientation for the oligopeptides in the assembling process, the electrospinning was applied. The as-spun fibers showed birefringent structure. However, no crystal diffraction was recognized in the selected-area electron diffraction analysis. To modify the crystallizing property of the oligopeptides, the superheated water treatment was conducted and the cystine and/or cysteine residues were completely destroyed. Then the entities from the aqueous solution of the treated oligopeptides became crystalline. However the crystal growth stopped up to its diameter of $\sim 40 \mu \mathrm{m}$.
\end{abstract}

(Received 25 May, 2009 ; Accepted 10 July, 2009)

\section{Introduction}

Keratin is abundantly present in nature and is the major component of hair, wool, feather, nail, and horns. Thus keratin is nothing but absolutely one of the most important resources of amino acids for the synthesis of other biopolymers.

On the one hand the understanding of selfassembling mechanism of soluble oligopeptides from keratin is of scientific interest in the design and fabrication of tissue structure. Brush [1] investigated the fundamental filamentation conditions of soluble $\mathrm{S}-\mathrm{H}$ proteins from avian keratin and reported that the threshold concentration of oligopeptides is $0.5 \mathrm{mg} / \mathrm{mL}$ and optimal pH 6.5 in $0.02 \mathrm{M} \mathrm{N}$-ethyl morpholine buffer. In this case formed filament structure seems to be amorphous since only three X-ray diffractions including amorphous halo of $0.47 \mathrm{~nm}$ [2] have been observed. To obtain the soluble avian keratin oligopeptides which can crystallize in the self-assembling process, the modification of the sequence of amino acids with superheated water is useful [3]. After the treatment at $220{ }^{\circ} \mathrm{C}$ for $2 \mathrm{~h}$ in superheated water, the cystine and/or cysteine residues are completely destroyed, and the formation of $\mathrm{H}_{2} \mathrm{~S}$ gas is noticed. The obtained oligopeptides tend to crystallize from their solutions at room temperature as the vaporization of solvent water proceeds. However the concentration of oligopeptides achieved in the dissolution with superheated water is no more than $20 \mathrm{mg} / \mathrm{mL}$.

From the viewpoints of productivity and economy the hydrolysis treatment with alkali is convenient for the production of soluble oligopeptides from keratin. When the biodegraded woods or chemically damaged vegetable fibers are treated with the oligopeptides prepared via the dissolution of feather keratin using alkali, the bending and tensile strengths have been enhanced $[4,5]$. These effects are probably brought about by the self-assembled oligopeptides settled in the defects of specimen. However the self-assembling behavior for this material has not been investigated.

In the present paper the oligopeptides of 1.5-2.0 kDa from waterfowl feather were prepared via the alkaline hydrolysis process and the self-assembling behavior was investigated using a transmission electron microscope (TEM). Moreover the superheated water treatment was conducted to the oligopeptides and the selected-area electron diffraction (SAED) studies were made on the obtained crystals. 


\section{Experimental}

\subsection{Materials}

Water-soluble feather keratin powder KERATIDE ${ }^{\circledR}$ (Toyo Feather Industry Co.,Ltd., Kanagawa, Japan) was used. This powder is produced from waterfowl feather via the alkaline hydrolysis dissolution process. The molecular weight is controlled in the range of 1.5-2.0 $\mathrm{kDa}$. Amino acid composition for this material is listed on Table 1. The measurements were made as follows. Waterfowl feather or the keratin powder was hydrolyzed with vaporized $\mathrm{HCl}$ at $150{ }^{\circ} \mathrm{C}$ in a pressure cell for $1 \mathrm{~h}$. After neutralized with trimethylamine, the obtained hydrolysate was subjected to the conversion treatment with phenylthiocarbamyl (PTC). Amino acid composition was measured using a HPLC system 8020 (TOSOH, Tokyo, Japan). When the amino acid compositions are compared between chicken feather [3] and waterfowl one, remarkable differences can be recognized especially in the amounts of Ser, Cys. That is waterfowl feather keratin is rich in Ser and poor in Cys, which suggests that waterfowl feather tends to be more easily dissolved as compared with chicken.

\subsection{Superheated water treatment}

The keratin powder was sealed in a stainless steel pressure cell with water at a concentration of $20 \mathrm{mg} / \mathrm{mL}$ and placed in an air oven. The superheated water treatments were made at $220{ }^{\circ} \mathrm{C}$ for $2 \mathrm{~h}$.

\subsection{Electrospinning}

Electrospinning was made using the keratin powder. A $30 \mathrm{wt} \%$ solution of keratin powder in $1,1,1,3,3,3$ hexafluoro-2-propanol (HFIP) was prepared. The spinning was carried out with an Esprayer ES-1000

Table. 1 Amino Acid Composition

\begin{tabular}{|c|c|c|c|}
\hline \multicolumn{2}{|c|}{ Amino acid } & $\begin{array}{c}\text { Amono acid } \\
\text { composition of } \\
\text { original } \\
\text { waterfowl } \\
\text { feather }(\mathrm{mol} \%)\end{array}$ & $\begin{array}{c}\text { Amono acid } \\
\text { composition of } \\
\text { hydrolysate, } \\
\text { KERATIDE® } \\
(\mathrm{mol} \%)\end{array}$ \\
\hline asparaginine & Asp & 6.9 & 8.0 \\
\hline glutamic acid & Glu & 10.4 & 9.5 \\
\hline serine & Ser & 22.0 & 10.2 \\
\hline threonine & Thr & 6.0 & 1.7 \\
\hline tyrosine & Tyr & 2.8 & 2.3 \\
\hline lysine & Lys & 0.3 & 0.6 \\
\hline arginine & Arg & 3.6 & 2.9 \\
\hline histidine & His & 2.5 & 0.2 \\
\hline glycine & Gly & 14.3 & 18.2 \\
\hline cystine & (Cys) 2 & 1.3 & 0.6 \\
\hline methionine & Met & 1.1 & 0.3 \\
\hline alanine & Ala & 2.9 & 7.7 \\
\hline valine & Val & 4.3 & 7.3 \\
\hline proline & Pro & 13.6 & 15.7 \\
\hline isoleucine & Ile & 1.9 & 3.8 \\
\hline leucine & Leu & 4.2 & 7.8 \\
\hline phenylalanine & Phe & 2.1 & 3.2 \\
\hline \multicolumn{2}{|l|}{ Total } & 100.2 & 100.0 \\
\hline
\end{tabular}

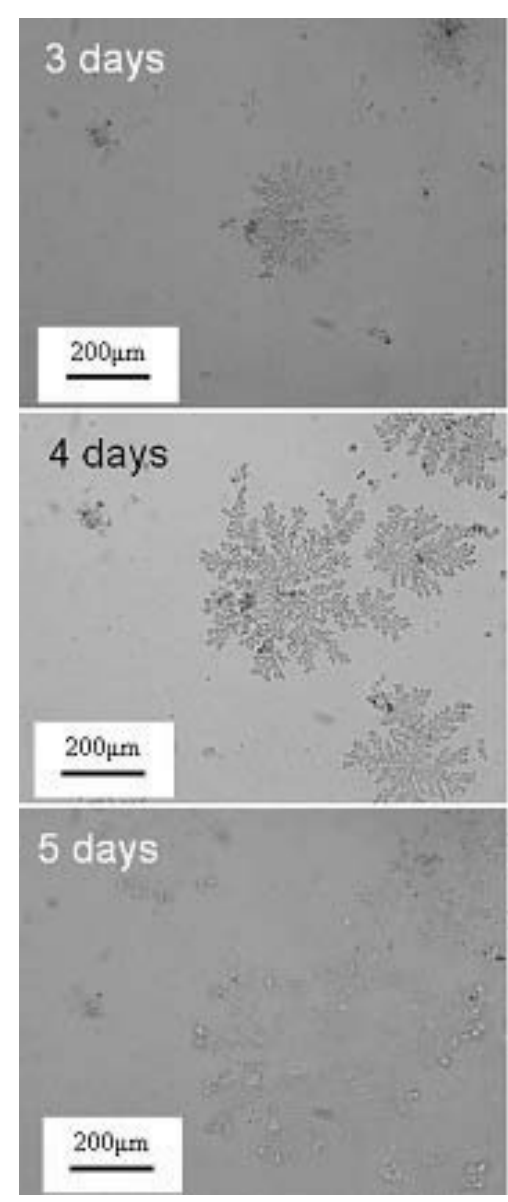

Fig. 1 Optical micrographs as viewed without cross polars for the dendrite-like self-assembled entities derived on a glass slide from an aqueous solution of keratin powder of $20 \mathrm{mg} / \mathrm{mL}$.

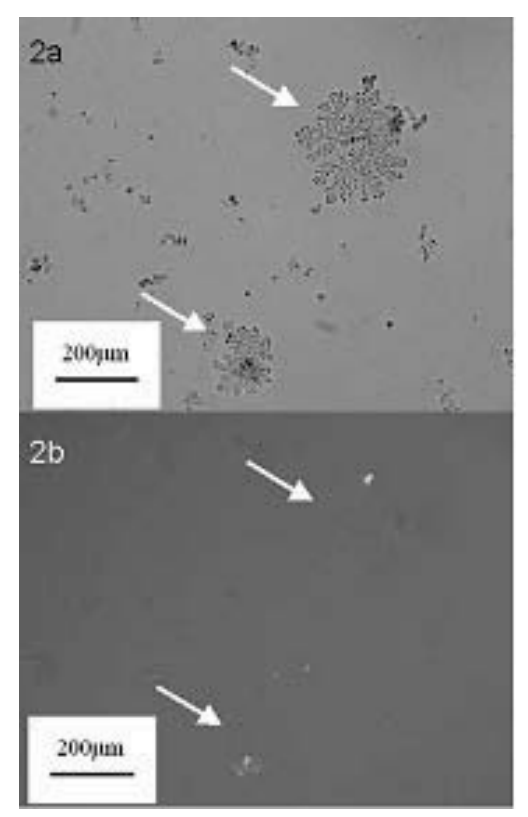

Fig. 2 Optical micrographs for the dendrite-like selfassembled entities derived on a glass slide from an aqueous solution of keratin powder of $20 \mathrm{mg} /$ $\mathrm{mL}$ as viewed without cross polars, Fig. 2a; between cross polars, Fig. $2 b$. 
(fuence Co., Ltd., Japan) equipped with a normal single metal plate as a collector. The solution was loaded into a glass syringe having a needle made of stainless steel. The needle was connected to a high-voltage supply. The solution was continuously supplied using a syringe pump at a rate of $20 \mathrm{~L} / \mathrm{min}$ through the needle. A voltage of $20 \mathrm{kV}$ was applied for electrospinning. The distance between the needle tip and the collector was ca. $10 \mathrm{~cm}$.

\subsection{TEM observation}

For TEM observation, as-spun nanofibers were mounted on carbon- or Al-coated copper grids by directly transferring them from the collector to the grid. Morphological observations and SAED studies were performed at room temperature using a JEM-200CX (JEOL Ltd., Japan) microscope operated at an accelerating voltage of $200 \mathrm{kV}$. Images and SAED patterns were recorded on Mitsubishi MEM (Mitsubishi Paper Mills Ltd., Tokyo) or Kodak SO-163 (Kodak Japan Ltd., Tokyo) photographic film.

\section{Results and discussion}

\subsection{Self-assembling behavior for the oligopeptides prepared from the alkaline hydrolysis}

A drop of $20 \mathrm{mg} / \mathrm{mL}$ solution of feather keratin powder was put on a clean glass slide and the glass was left for $10 \mathrm{~min}$ in normal laboratory air, then the glass slide was set in a clean box at room temperature. The dendrite-like entities were observed to grow as the vaporization of solvent water proceeded (see Fig. 1). However the entities were destroyed suddenly and spontaneously when they were dried up after leaving for 5 days (see Fig. 1, bottom). The fragile nature of the dendrite-like entities is probably related to the smaller amount of Cys content (see Table 1). It is well known that some specific amino residues e.g. Cys, Thr, Ser, Arg tend to be destroyed during the alkaline hydrolysis process [6]. When the values in the columns 2 and 3 of Table 1 are compared similar tendency can be seen. The amount of Cys has been decreased to $0.6 \mathrm{~mol} \%$ although the native chicken feather contains more than $7 \mathrm{wt} \%$ [3]. Therefore the number of S-S bondings generated between the adjacent oligopeptides which stabilize the structure assembled has become smaller as compared with the case of the filamentation tests using soluble S-H proteins [1]. Thus the entities observed in this study have become fragile. The dendrite-like entities obtained after leaving the specimen for 3 days did not show birefringent structure (see Fig. 2).

The orientation of molecular chains in the solution or melt of conventional polymers is usually effective for the nucleation of crystallites leading to the formation of higher order structure [7]. For the enhancement of molecular orientation in polymer solution, the electrospinning is convenient. The authors have succeeded in the production of partially oriented nanofibers from polydioxanone [8,9], poly (heptamethylene terephthalate) [10] using HFIP for the solvent. Moreover the vaporization of solvent that occurs on the spin-line will promote the crystallization of oligopeptides similarly as the crystallization on a glass slide by the vapor diffusion [3]. HFIP was also used for the solvent instead of water since the vaporization of water was not fully completed in the course of spinning. When the concentration of the solution was lower than $30 \mathrm{wt} \%$, it was difficult to obtain fibers due to the lower molecular weight of the keratin powder.

Fig. 3a is an optical micrograph for the as-spun keratin fibers recorded under the crossed polars. It is seen that the as-spun fibers have birefringent structures. Fig. $3 \mathrm{~b}$ and Fig. $3 \mathrm{c}$ are the TEM image and the corresponding SAED pattern for the as-spun fibers, respectively. No crystal diffraction can be seen in the SAED pattern. In addition the halo scattering from keratin do not concentrate on the equator. The electrospinning is useful to produce birefringent structures. However the obtained molecular orientation along fiber axis has not become so high as to make the concentration of halo scattering on the equator. In the electrospinning of silk fibroin using HFIP as solvent similar phenomenon in the molecular orientation has been recognized [11].

It seems to be difficult to crystallize the oligopeptides prepared via the alkaline hydrolysis process by only controlling the assembling conditions.

\subsection{Influence of superheated water treatment on assembling behavior of oligopeptides}

The complete destruction of Cys residues is proved to be a key process to modify the nature of the oligopeptides to be crystalline [3]. Thus the superheated water treatment was conducted.

Fig. 4a shows the self-assembled entities from the aqueous solution of the oligopeptides subjected to the superheated water treatment as viewed between cross polars. Needle-like birefringent entities have been observed to grow. Any heterogeneity present on the glass slide seems to have promoted the generation of the entities. In addition, the entities are stable after dried in air. The entities show similar shape as the crystals in the previous report [3]. However the crystal growth has stopped up to its diameter of $\sim 40 \mu \mathrm{m}$. Fig. $4 \mathrm{~b}$ is the TEM 

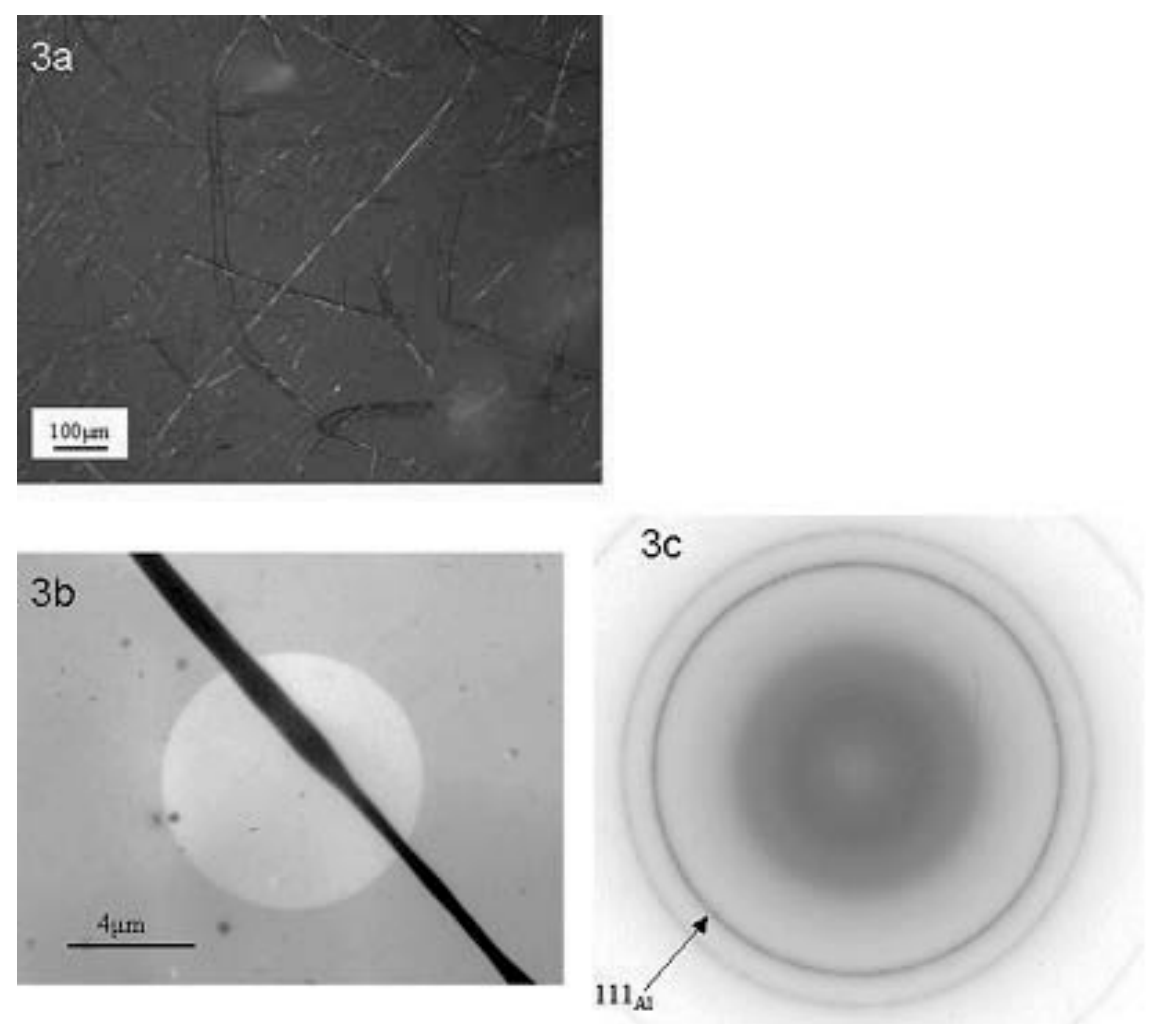

Fig. 3 Electrospun fibers as viewed between cross polars, Fig. 3a; the TEM image for the fiber, Fig. 3b. Fig. 3c is the SAED pattern obtained from the fiber in the encircled area of Fig. $3 b$.
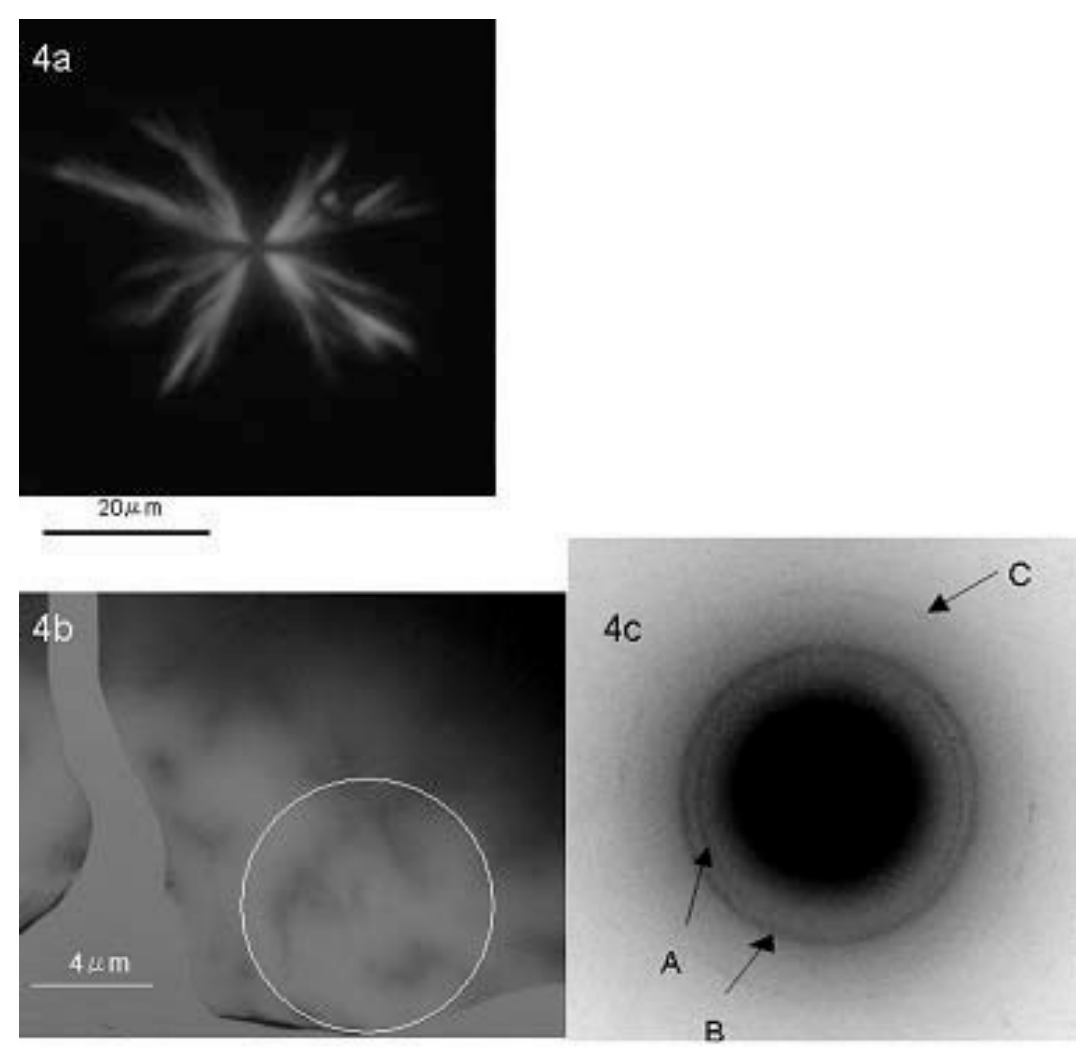

Fig. 4 Self-assembled entities as viewed between cross polars grown from a $20 \mathrm{mg} / \mathrm{mL}$ aqueous solution of oligopeptides subjected to the superheated water treatment, Fig. 4a; the TEM image for the self-assembled entities, Fig. 4b. Fig. 4c is the SAED pattern for the self-assembled entities in the encircled area of Fig. 4b. The characters $\mathrm{A}, \mathrm{B}$, and $\mathrm{C}$ indicate the observed diffractions. 
image for the needle-like birefringent entities. Fairly ambiguous shadows of needle-like entities can be recognized beyond the frame of TEM grid. Fig. $4 \mathrm{c}$ is the corresponding SAED pattern for the entities. Electron beam scattering has smeared the diffractions of $d$-spacings larger than $\sim 0.6 \mathrm{~nm}$. Three diffractions can be seen on the SAED pattern. (A) and (C) diffractions are discontinuous, which is due to the crystallographic effect of the specimen on the TEM grid. The $d$-spacings calculated from the diffractions are as follows, (A) 0.565 $\mathrm{nm}$, (B) $0.476 \mathrm{~nm}$, (C) $0.345 \mathrm{~nm}$. These values coincide with the previous data, and (B) is amorphous halo [2]. The oligopeptides have become crystalline after the superheated water treatment. However the crystal growth has stopped in an early stage. At crystallization it is probable that the damage to the sequence of amino acids during the chemical and/or the heat treatments will increase the generation of crystal faults, and will affect the crystal growth.

\section{Conclusion}

The oligopeptides prepared from the alkaline hydrolysis process will generate dendrite-like entities of amorphous structure with fragile nature. The fragile property of the entities is probably due to the smaller Cys content of $0.6 \mathrm{~mol} \%$. However such small amount of Cys residue is enough to suppress the crystallization of the oligopeptides. The superheated water treatment is effective to modify the nature of the oligopeptides to be crystalline.

Acknowledgments : The authors thank Mr. Hideaki
Minami and Dr. Shigenori Nishiuchi for the superheated water treatment.

\section{References}

1. A. H. Brush, J. Protein Chem., 2, 63 (1983).

2. R. Schor and S. Krimm, Biophys. J., 1, 467 (1961).

3. J. Yin, S. Rastogi, A. E. Terry, and C. Popescu, Biomacromol ., 8, 800 (2007).

4. Y. Kawahara, R. Endo, and T. Kimura, Text. Res. J., 74, 93 (2004).

5. R. Endo, K. Kamei, I. Iida, and Y. Kawahara, J. Archaeological Sci., 35, 1240 (2008).

6. R. S. Asquith and N. H. Leon, "Chemistry of Natural Protein Fibers", (R. S. Asquith, R.S. Ed.) Plenum Press, New York, pp. 198-202 (1977).

7. J. M. Schultz, "Polymer Crystallization", Oxford, American Chemical Society: Washington, DC, pp. 113-117 (2001).

8. A. Nakayama, Y. Hayakawa, M. Tsuji, S. Kohjiya, and Y. Kawahara, Proceeding of $22^{\text {nd }}$ Annual Meeting of The Polymer Processing Society, G07-12 (2006).

9. A. Nakayama, Y. Kawahara, Y. Hayakawa, R. Takahashi, T. Yoshioka, and M. Tsuji, Sen'i Gakkaishi, 63, 230 (2007).

10. Y. Kawahara, S. Naruko, A. Nakayama, M. C. Wu, E. M. Woo, and M. Tsuji, Acta Cryst., A64 : C601 (2008).

11. Y. Kawahara, A. Nakayama, N. Matsumura, T. Yoshioka, and M. Tsuji, J. Appl. Polym. Sci., 107, 3681 (2008). 